\title{
Spontaneous cataract absorption in patients with leptospiral uveitis
}

\author{
S R Rathinam, P Namperumalsamy, Emmett T Cunningham Jr
}

\begin{abstract}
Aims-To describe the occurrence of spontaneous cataract absorption in patients with leptospiral uveitis.

Methods-The records of patients with seropositive leptospiral uveitis seen in the uveitis clinic at Aravind Eye Hospital between January 1994 and December 1997 were reviewed retrospectively.

Results-During the 4 years of the study, 394 eyes of 276 patients with seropositive leptospiral uveitis were identified. Of these, 54 eyes $(13.7 \%)$ of 41 patients $(14.9 \%)$ had a final visual acuity of $20 / 40$ or worse attributable to cataract formation. Of these 54 eyes, 41 eyes $(75.9 \%)$ had visually significant cataract on their first visit to the uveitis clinic, and 13 eyes $(24.1 \%)$ were noted to have cataract 1-6 months after presentation. Spontaneous absorption was observed in 10 eyes $(18.5 \%)$ of eight patients $(19.5 \%)$, and occurred from 6 weeks to 18 months, with a median of 5 months, after the onset of cataract. Of 12035 consecutive, non-leptospiral, nontraumatic, uveitic, control patients seen during the same 4 years of the study, none showed spontaneous cataract absorption. Conclusion-Spontaneous cataract absorption occurs in a significant number of patients with leptospiral uveitis, and appears to be unique to this form of non-traumatic uveitis.
\end{abstract}

Aravind Eye Hospital and Postgraduate Institute of Ophthalmology, Madurai, Tamil Nadu, India

S R Rathinam

P Namperumalsamy

The Francis I Proctor Foundation and The

Department of Ophthalmology, UCSF, Medical Center,

San Francisco,

California, USA

Emmett T Cunningham

$\mathrm{Jr}$

Correspondence to:

Dr Emmett T Cunningham

Jr, The Pearl and Samuel J

Kimura Ocular Immunology

Laboratory The Francis I

Proctor Foundation, UCSF,

Medical Center, San

Francisco, California

94143-0944, USA

emmett@itsa.ucsf.edu

Accepted for publication 25 April 2000
(Br F Ophthalmol 2000;84:1135-1141)

Leptospirosis results from infection with the waterborne spirochaete Leptospira. Human infection with Leptospira occurs worldwide, and is particularly prevalent in tropical and subtropical agricultural areas where exposure to infected animals and contaminated water are more common. Clinically, leptospiral infection may be occult, may produce a flu-like illness accompanied by fever, fatigue, arthralgia, and headache, or may result in fulminant, life threatening hepatorenal failure. ${ }^{12}$

Leptospiral uveitis is a frequent complication of systemic infection, and may even occur in large outbreaks following heavy rainfalls or flooding. ${ }^{3}$ One or both eyes may be involved, typically with either an anterior or diffuse uveitis, and often accompanied by hypopyon formation or retinal vasculitis. ${ }^{3}$ Therapy includes a 10 day course of intravenous penicillin or oral doxycycline given in conjunction with topical and/or periocular corticosteroids to treat the intraocular inflammation or its sequelae. Good or complete recovery of vision occurs in most patients following such treatment. ${ }^{3}$
Spontaneous cataract absorption is uncommon but can occur in the setting of traumatic capsular tears, ${ }^{4}$ and in congenital cataracts caused by rubella. ${ }^{5-7}$ While cataract is a frequent cause of vision loss in patients with uveitis, ${ }^{8}$ spontaneous absorption of opacified lens material is rare..$^{9-13}$ We describe a group of patients with leptospiral uveitis seen at Aravind Eye Hospital who developed uveitic cataracts, a significant percentage of whom showed spontaneous cataract absorption.

\section{Patients and methods}

The records of all patients seen in the uveitis clinic at the Aravind Eye Hospital between 1994 and 1997 who were diagnosed with leptospiral uveitis were reviewed retrospectively. In each case, a complete ophthalmic examination, including slit lamp biomicrocopy and indirect ophthalmoscopy, was performed by a single ophthalmologist (SRR). All microagglutination tests were performed by the leptospirosis reference laboratory at the Centers of Disease Control and Prevention (CDC), Atlanta, Georgia, according to a standard methodology. ${ }^{14}$ Other causes of uveitis were excluded by history, review of systems, physical examination, and directed use of laboratory and ancillary testing. ${ }^{15}{ }^{16}$ All patients with leptospiral uveitis were treated with oral doxycycline, $100 \mathrm{mg}$ twice daily for 10 days. In addition, anterior chamber inflammation was treated with intensive topical corticosteroids, whereas patients with diffuse uveitis were given both intensive topical corticosteroids and either oral, $1.0 \mathrm{mg} / \mathrm{kg}$, or a sub-Tenon depot $(40 \mathrm{mg} / \mathrm{ml})$ injection of prednisolone. A cycloplegic/mydriatic agent was also used in most patients. Cataracts were considered visually significant when they limited vision to 20/40 or worse. Patients were considered for cataract extraction and intraocular lens implantation when the cataract was visually significant, and the inflammation was under control for 3 months with or without corticosteroid cover.

Statistical significance and $\mathrm{p}$ values were determined by means of a $\chi^{2}$ test. When the expected number of individuals in a cell was less than five, a two tailed Fisher exact test was used.

\section{Results}

During the 4 years of the study, 394 eyes of 276 patients with seropositive leptospiral uveitis were identified. Of these 276 patients, 227 $(82.2 \%)$ were men and $49(17.8 \%)$ were women. Bilateral uveitis was identified in 118 patients $(42.8 \%)$, whereas 158 patients $(57.2 \%)$ had unilateral inflammation. Thirty 
Table 1 Clinical findings in patients with leptospiral uveitis and spontaneous cataract absorption

\begin{tabular}{|c|c|c|c|c|c|c|c|}
\hline $\begin{array}{l}\text { Case } \\
\text { No }\end{array}$ & Age/sex & $\begin{array}{l}\text { Presenting } \\
\text { vision }\end{array}$ & Eye findings & $\begin{array}{l}\text { Time from } \\
\text { presentation to } \\
\text { cataract }^{\star}\end{array}$ & $\begin{array}{l}\text { Duration between } \\
\text { cataract onset } \\
\text { and absorption * }\end{array}$ & Surgery & Final vision \\
\hline 1 & $29 / \mathrm{M}$ & $\begin{array}{l}\text { HM RE } \\
20 / 20 \mathrm{LE}\end{array}$ & $\begin{array}{l}\text { Anterior uveitis RE } \\
\text { with: hypopyon; } \\
\text { posterior synechiae; } \\
\text { partially absorbed } \\
\text { cataract }\end{array}$ & 0 & 0 & $\begin{array}{l}\text { Refused surgery } \\
\text { RE }\end{array}$ & $\begin{array}{l}\text { HM RE } \\
20 / 20 \mathrm{LE}\end{array}$ \\
\hline 2 & $24 / M$ & $\begin{array}{l}20 / 30 \mathrm{RE} \\
\mathrm{HM} \mathrm{LE}\end{array}$ & $\begin{array}{l}\text { Anterior uveitis LE } \\
\text { with cataract }\end{array}$ & $\begin{array}{l}1 \text { month RE } \\
0 \mathrm{LE}\end{array}$ & $\begin{array}{l}4.5 \text { months RE } \\
5 \text { months LE }\end{array}$ & $\begin{array}{l}\text { PC IOL both } \\
\text { eyes }\end{array}$ & $20 / 20$ both eyes \\
\hline 3 & $23 / \mathrm{M}$ & $\begin{array}{l}20 / 20 \text { both } \\
\text { eyes }\end{array}$ & $\begin{array}{l}\text { Anterior uveitis RE, } \\
\text { Diffuse uveitis with } \\
\text { Koeppe nodules and } \\
\text { snowbanking LE }\end{array}$ & $\begin{array}{l}1 \text { month RE } \\
2 \text { months LE }\end{array}$ & $\begin{array}{l}6 \text { months RE } \\
1 \text { month LE }\end{array}$ & $\begin{array}{l}\text { PC IOL both } \\
\text { eyes }\end{array}$ & $20 / 20$ both eyes \\
\hline 4 & $32 / \mathrm{M}$ & BE-6/18 & $\begin{array}{l}\text { Diffuse uveitis with } \\
\text { posterior synechiae } \\
\text { and optic disc } \\
\text { oedema both eyes }\end{array}$ & $\begin{array}{l}2.5 \text { weeks } \mathrm{RE} \\
0 \mathrm{LE}\end{array}$ & 9 months RE & $\begin{array}{l}\text { PC IOL both } \\
\text { eyes }\end{array}$ & $20 / 20$ both eyes \\
\hline 5 & $19 / M$ & $\begin{array}{l}\text { HM RE } \\
\text { 20/20 LE }\end{array}$ & $\begin{array}{l}\text { Anterior uveitis with } \\
\text { hypopyon posterior } \\
\text { synechiae, and } \\
\text { cataract RE }\end{array}$ & 0 & 10 days & $\begin{array}{l}\text { AC IOL } \\
\text { (capsular tear) }\end{array}$ & $20 / 30$ \\
\hline 6 & $29 / M$ & $\begin{array}{l}\text { 20/20 RE } \\
\text { 20/30 LE }\end{array}$ & $\begin{array}{l}\text { Diffuse uveitis with } \\
\text { hypopyon, posterior } \\
\text { synechiae, and } \\
\text { cataract LE }\end{array}$ & 2.5 months LE & 9 months LE & PC IOL LE & $20 / 20$ both eyes \\
\hline 7 & $27 / \mathrm{F}$ & $\begin{array}{l}\text { HM RE } \\
20 / 20 \mathrm{LE}\end{array}$ & $\begin{array}{l}\text { Diffuse uveitis with } \\
\text { hypopyon, posterior } \\
\text { synechiae, and } \\
\text { cataract RE. }\end{array}$ & $0 \mathrm{RE}$ & 2 months RE & $\begin{array}{l}\mathrm{ECCE} / \mathrm{no} \mathrm{IOL} \\
\mathrm{RE}\end{array}$ & $\begin{array}{l}\text { 20/30 RE } \\
\text { 20/20 LE }\end{array}$ \\
\hline 8 & $23 / \mathrm{M}$ & $\begin{array}{l}\text { 20/20 RE } \\
\text { HM OS }\end{array}$ & $\begin{array}{l}\text { Diffuse uveitis with } \\
\text { hypopyon, posterior } \\
\text { synechiae, and } \\
\text { cataract LE. }\end{array}$ & $0 \mathrm{LE}$ & 2 months LE & PC IOL LE & $\begin{array}{l}\text { 20/20 RE } \\
\text { 20/30 LE }\end{array}$ \\
\hline
\end{tabular}

*Cataract present on first examination.

eight patients $(13.8 \%)$ presented with anterior uveitis, and 238 patients $(86.2 \%)$ showed evidence of diffuse inflammation. Of the 394 eyes with leptospiral uveitis, 54 eyes $(12.9 \%)$ had visually significant cataract. Cataract was identified in 41 of the affected eyes $(75.9 \%)$ at first visit to the hospital, whereas it was noted on a subsequent visit 1-6 months after presentation in 13 eyes $(24.1 \%)$ of nine patients, with a median time of 2 months after onset of uveitis. The duration of eye symptoms before presentation was 3 months or less in $78 \%$ of patients. Follow up ranged from 1 month to 3 years, with a median follow up time of 1 year.

Of the 54 eyes of cataract, 10 eyes $(18.5 \%)$ of eight patients $(19.5 \%)$ showed spontaneous cataract absorption (Table 1). The time from first observing the cataract to complete absorption ranged from 6 weeks to 18 months, with a median of 5 months. The age range and median, as well as the serovar distribution of patients with leptospiral uveitis with and without cataract, including those in the latter group that showed spontaneous absorption, are shown in Table 2 . The most commonly identified serovars were the L autumanlis, L pomona, and $L$ bratislava. The median age and frequency of the various serovars among these three groups of patients showed no statistical differences. Table 3 compares the ocular findings present in the 54 eyes with cataract with those in the 343 eyes without cataract. Findings significantly associated with the formation of cataract in patients with leptospiral uveitis included posterior synechiae formation $(\mathrm{p}=0.012)$, hypopyon formation $(p=0.00012)$, and retinal vasculitis $(p=0.00026)$. Papillitis $(p=0.35)$, vitreous cells $(\mathrm{p}=0.47)$, and vitreous opacities $(\mathrm{p}=0.14)$, although present in a sizeable proportion of patients, were not observed more frequently in patients who developed cataract or whose cataract, once developed, showed spontaneous absorption.

Of the 54 eyes with cataract, 30 had cataract extraction with posterior chamber lens implantation. One eye with cataract received an anterior chamber lens implantation following posterior capsular rupture. Of these 31 eyes that underwent cataract extraction and intraocular lens placement, none had a recurrence of their inflammation, and $27(87.1 \%)$ had a final visual acuity of $20 / 30$ or better following surgery. Of the remaining four eyes of the two patients who underwent cataract extraction and whose vision remained below 20/200, two eyes had an epiretinal membrane, and two eyes had prior exudative retinal detachments with atrophy of the underlying retinal pigment epithelium. Of the 19 patients who refused cataract surgery, vision was $20 / 60$ in six patients and they chose to postpone the surgery. Thirteen patients refused cataract surgery in spite of their poor visual acuity, which was below 20/60 in each case. Of the 10 eyes that showed spontaneous cataract absorption, seven received posterior chamber intraocular lenses, and each achieved a final visual acuity of $20 / 30$ or better. The remaining patients (three patients, three eyes) refused surgical treatment.

During the same 4 years of the study, 12035 consecutive, non-leptospiral, uveitic, non-traumatic, control patients were seen in the uveitis clinic at Aravind Eye Hospital, and none showed spontaneous cataract absorption.

CASE 1

A 29 year old male farmer from a small village consulted a local physician complaining of fever and fatigue of 10 days' duration. He was treated empirically with broad spectrum antibiotics. 
Table 2 Age and serovar distribution in patients with leptospiral uveitis

\begin{tabular}{|c|c|c|c|c|c|c|}
\hline \multirow[b]{2}{*}{ Age (years) } & \multicolumn{2}{|c|}{$\begin{array}{l}\text { Eyes without cataract } \\
(n=235)\end{array}$} & \multicolumn{2}{|c|}{$\begin{array}{l}\text { Eyes with cataract } \\
(n=41)\end{array}$} & \multicolumn{2}{|c|}{$\begin{array}{l}\text { Spontaneous absorption of } \\
\text { cataract }(n=8)\end{array}$} \\
\hline & & & & & & \\
\hline Range & \multirow{2}{*}{\multicolumn{2}{|c|}{$\begin{array}{l}8-80 \\
31\end{array}$}} & \multirow{2}{*}{\multicolumn{2}{|c|}{$\begin{array}{l}12-62 \\
28\end{array}$}} & \multicolumn{2}{|c|}{$19-32$} \\
\hline Median & & & & & 25 & \\
\hline $\begin{array}{l}\text { Serovar } \\
\text { distribution }\end{array}$ & No & $\%$ & No & $\%$ & No & $\%$ \\
\hline$L$ autumnalis & 44 & 20 & 16 & 37 & 4 & 40 \\
\hline$L$ pomona & 32 & 14 & 5 & 12 & 1 & 10 \\
\hline$L$ bratislava & 26 & 12 & 13 & 30 & 3 & 30 \\
\hline$L$ australis & 24 & 11 & 2 & 5 & & \\
\hline L bulgarica & 23 & 10 & & & & \\
\hline$L$ patoc & 19 & 8 & & & & \\
\hline L canicola & 11 & 5 & 2 & 5 & & \\
\hline L hardjo & 9 & 4 & 1 & 2 & & \\
\hline \multicolumn{7}{|l|}{ L icterohaemo- } \\
\hline rrhagiae & 7 & 3 & 1 & 2 & 1 & 10 \\
\hline$L$ jegathlara & 6 & 3 & & & & \\
\hline L javanica & 4 & 2 & & & & \\
\hline$L$ wolffi & 3 & 1.3 & & & & \\
\hline$L$ copenhageni & 3 & 1.3 & 1 & 2 & 1 & 10 \\
\hline$L$ djasiman & 2 & 1 & & & & \\
\hline L panama & 2 & 1 & & & & \\
\hline$L$ semarenga & 2 & 1 & 1 & 2 & & \\
\hline$L$ alexi & 2 & 1 & & & & \\
\hline L cellodoni & 1 & 0.4 & & & & \\
\hline L grippotyphosa & 1 & 0.4 & & & & \\
\hline$L$ medanesis & 1 & 0.4 & & & & \\
\hline L robinsoni & 1 & 0.4 & & & & \\
\hline L georgia & 1 & 0.4 & 1 & 2 & & \\
\hline
\end{tabular}

The total number of seroreactions exceeds the total number of patients because some patients tested positive for two or more serovars.

Table 3 Ocular findings by lens status in patients with leptospiral uveitis

\begin{tabular}{|c|c|c|c|c|c|}
\hline & \multicolumn{2}{|l|}{ Cataract } & \multicolumn{2}{|l|}{ No cataract } & \multirow[t]{2}{*}{$p$ Value } \\
\hline & $N=54$ (eyes) & $\%$ & $N=343$ (eyes) & $\%$ & \\
\hline Posterior synechiae & 24 & 47.1 & 101 & 29.4 & $0.012^{\star}$ \\
\hline Hypopyon & 21 & 41.2 & 61 & 17.8 & $0.00012^{\star}$ \\
\hline Vasculitis & 9 & 17.6 & 153 & 44.6 & $0.00026^{\star}$ \\
\hline Papillitis & 12 & 23.5 & 62 & 18.1 & 0.35 \\
\hline Vitreous cells & 39 & 76.5 & 277 & 80.8 & 0.47 \\
\hline Vitreous opacities & 24 & 47.1 & 125 & 36.4 & 0.14 \\
\hline
\end{tabular}

${ }^{\star}$ Statistically significant.

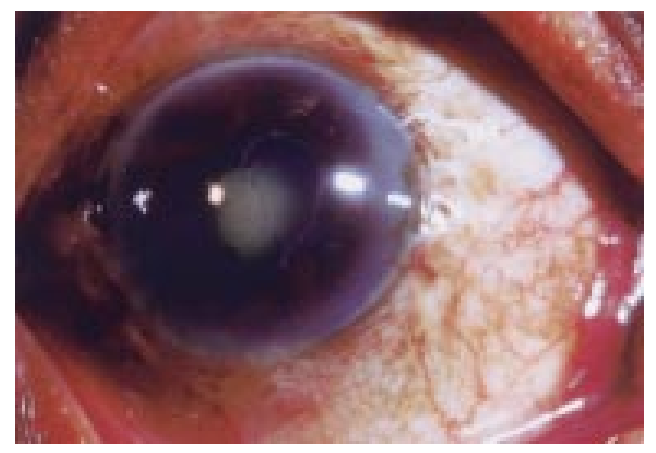

Figure 1 Photograph of the right eye of case 1 three months after presentation showing both anterior and posterior synechiae, and a shadow on the anterior surface of the partially absorbed lens. The patient refused surgery and was subsequently lost to follow up.

the patient refused surgical treatment. The patient was lost to follow up.

CASE 2

A 24 year old male farmer developed fever, malaise, arthritis, and headache of 1 week's duration. He was seen by a local physician who obtained a complete blood count, a chest $x$ ray, syphilis serologies, and a Widal test and peripheral smear for malarial parasites, all of which were negative. The patient was treated empirically with broad spectrum antibiotics and slowly improved. Eight months later he developed pain, redness, and decreased vision in each eye, and was referred to Aravind Eye Hospital. Initial examination revealed a best corrected vision of right eye 20/60, left eye hand movement. Intraocular pressure by applanation was $12 \mathrm{~mm}$ $\mathrm{Hg}$ bilaterally. Slit lamp examination revealed

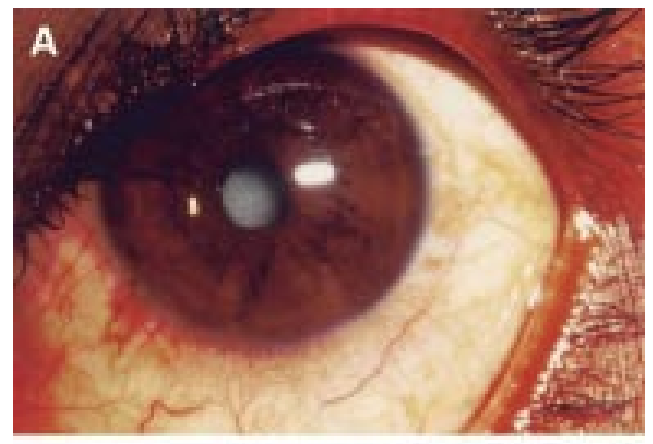

Three months later the patient noted pain, redness, and decreased vision in each eye, and was referred to Aravind Eye Hospital. Best corrected vision was right eye hand movement, left eye $20 / 20$. Intraocular pressure by applanation was $17 \mathrm{~mm} \mathrm{Hg}$ bilaterally. Examination of right eye revealed a severe, non-granulomatous anterior uveitis with hypopyon formation, scattered posterior and anterior synechiae, and a mature and partially absorbed cataract. The right posterior segment was not visible. The left eye showed mild, diffuse uveitis with patchy retinal vasculitis. Laboratory investigations, including a complete blood count, a serum angiotensin converting enzyme (ACE), syphilis serologies, a chest $x$ ray, and skin testing with purified protein derivative (PPD), were all normal. A microagglutination test for Leptospira was positive for the $L$ pomona at 1:100 dilution. The patient was treated with oral doxycycline, $100 \mathrm{mg}$ twice daily for 10 days, and oral prednisolone, $40 \mathrm{mg}$ daily for 1 week followed by a slow, 2 month taper. Topical corticosteroids and a cycloplegic/ mydriatic agent were also given. The uveitis was controlled but within 3 months the cataract in the right eye showed significant absorption (Fig 1). Extracapsular removal of the residual cortical material followed by placement of a posterior chamber intraocular lens was recommended but

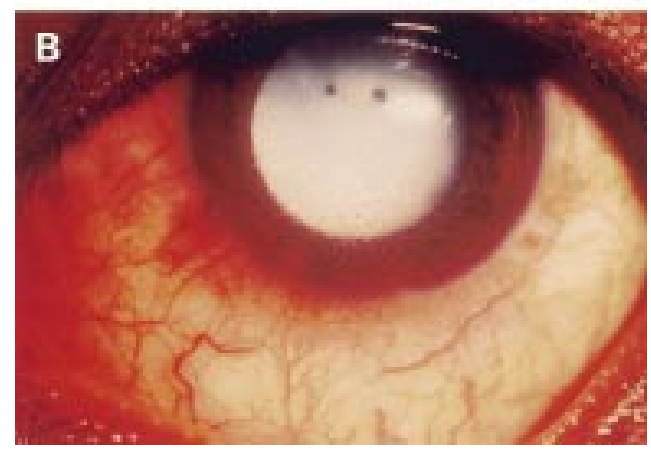

Figure 2 Photograph of the left eye of case 2 at presentation showing numerous granulomatous keratic precipitates. Before dilatation a shadow is visible on the anterior surface of the partially absorbed lens $(A)$.

Dilatation reveals that the superior portion of the lens is nearly completely absorbed (B). The right eye also had a cataract which eventually absorbed completely. 
moderate, bilateral granulomatous anterior uveitis as well as cataract formation in both eyes. The cataract in the left eye was worse, and showed partial absorption (Fig 2). Posterior segment examination in the right eye was unremarkable. The left fundus was not visible. Microagglutination for Leptospira was positive for $L$ bratislava at 1:100 dilution. The patient was treated with oral doxycycline, $100 \mathrm{mg}$ twice daily for 10 days, and oral prednisolone, $40 \mathrm{mg}$ daily for 1 week with a slow, 2 month tapering. Four months after presentation the intraocular inflammation was controlled but the left cataract was nearly completely absorbed. The residual cortical material was removed surgically, and a posterior chamber intraocular lens was implanted. Shortly after surgery the lens in the right eye became white and the vision dropped to $2 / 60$. During the subsequent 8 months cataract absorption began in the right eye, and an extracapsular cataract extraction with posterior chamber lens implantation was performed. Vision stabilised at 20/20 in each eye following surgery.

CASE 3

A 23 year old man from a region known to be endemic for leptospirosis presented to Aravind Eye Hospital with a 3 day history of right eye pain and redness. Medical history was significant for fever and severe fatigue approximately 1 year before presentation, when he was exposed to flooding after heavy rainfall approximately 2 days before the onset of fever. He had been treated empirically with broad spectrum antibiotics and improved. Initial examination revealed a best corrected vision of $20 / 20$ bilaterally. Intraocular pressure by applanation was $14 \mathrm{~mm} \mathrm{Hg}$ in each eye. Examination of the right eye was unremark-
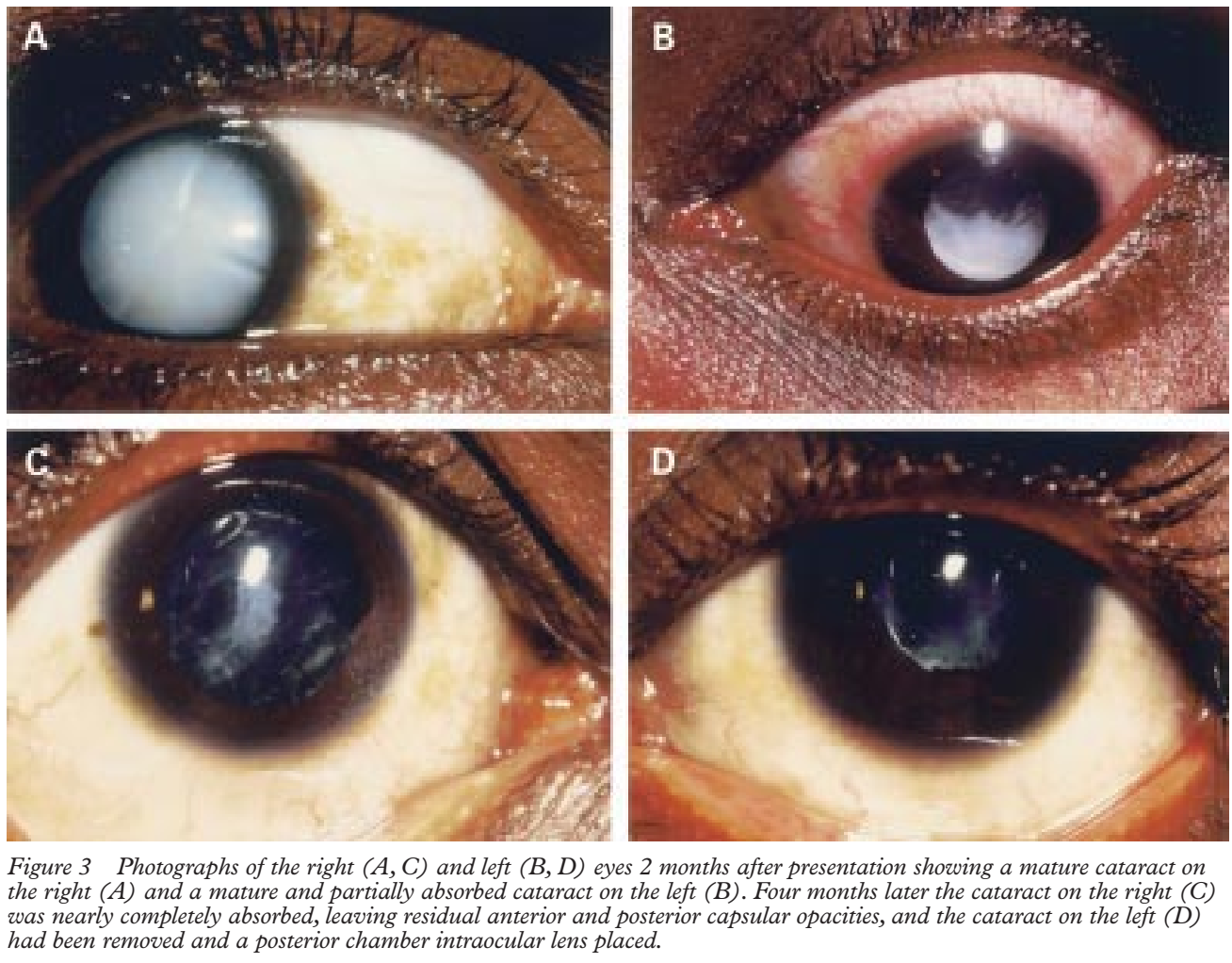

Figure 3 Photographs of the right $(A, C)$ and left $(B, D)$ eyes 2 months after presentation showing a mature cataract on the right $(A)$ and a mature and partially absorbed cataract on the left $(B)$. Four months later the cataract on the right $(C)$ was nearly completely absorbed, leaving residual anterior and posterior capsular opacities, and the cataract on the left (D) had been removed and a posterior chamber intraocular lens placed.

able. Slit lamp examination of the left eye showed moderate non-granulomatous anterior chamber inflammation with formation of a small hypopyon. Examination of the left posterior segment showed moderate vitreous inflammation and mild optic disc oedema. Laboratory investigations including syphilis serologies, a chest $x$ ray, skin testing with PPD, and HLA-B27 were negative. The microagglutination test for Leptospira was positive for the $L$ autumanlis and $L$ bratislava at 1:3200 dilution. The patient was treated with doxycycline, $100 \mathrm{mg}$ twice daily, a sub-Tenon corticosteroid injection, topical corticosteroids, and a cycloplegic/mydriatic agent. The patient responded quickly but returned 4 months later with bilateral, non-granulomatous anterior uveitis worse on the left. Best corrected vision was right eye $20 / 20$, left eye $20 / 40$. In addition to the anterior chamber inflammation, slit lamp examination showed early cataractous changes in the left lens. The patient responded quickly to a second course of corticosteroids but returned 2 months later with recurrent bilateral diffuse uveitis. Best corrected vision was right eye 6/60; left eye hand movement. Intraocular pressure by applanation was right eye $17 \mathrm{~mm} \mathrm{Hg}$; left eye $2 \mathrm{~mm} \mathrm{Hg}$. Slit lamp examination showed non-granulomatous inflammation with early cataract on the right, and a hypopyon and a mature cataract on the left. Topical, periocular, and oral corticosteroids were restarted. Within 1 month, however, the cataract on the right progressed to maturation (Fig 3A) and the previously mature cataract on the left was found to be completely absorbed leaving the capsule behind (Fig 3B). After the inflammation was controlled, a posterior chamber intraocular lens was implanted

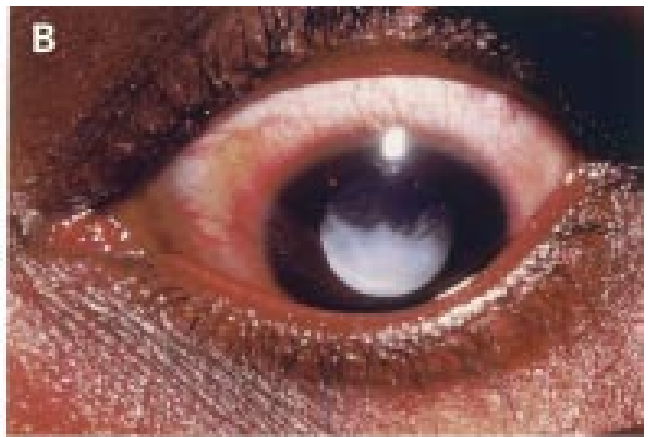



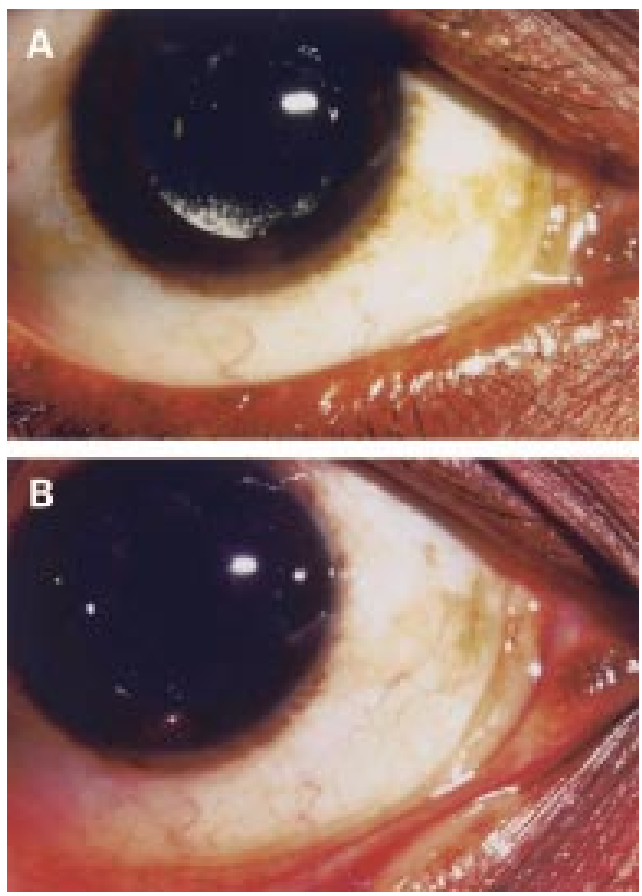

Figure 4 Photograph of the left eye of case 4 showing total cataract absorption 9 months after presentation (A). Vision was 20/20 with $a+10$ dioptre lens placed in front of the eye. Best corrected vision remained 20/20 following placement of a posterior chamber intraocular lens (B).

on the left (Fig 3D). During his postoperative follow up for left eye, the cataract in the right eye showed nearly complete absorption (Fig 3C). The patient then underwent cataract extraction and posterior chamber intraocular lens implantation of the right eye. Vision at last follow up was $20 / 20$ in each eye.

CASE 4

A 32 year old male farmer presented with a 1 week history of right eye pain, redness, and decreased vision. Medical and ocular history were otherwise unremarkable. Best corrected visual acuity was right eye 20/60; left eye 20/40. Slit lamp examination showed moderate, non-granulomatous anterior chamber inflammation, worse on the right, and mild posterior subcapsular cataract on the left. Posterior segment examination revealed mild vitreous inflammation and optic disc oedema in both eyes. The presentation was believed at first to represent non-specific, endogenous uveitis and the patient was treated with oral prednisolone, and bilateral, topical corticosteroid and cycloplegics. The patient returned 1 month later with minimal residual inflammation but a white mature cataract on the left. Best corrected visual acuity was right eye 20/20; left eye $20 / 200$. The rapid cataract progression suggested that the uveitis might be leptospiral, and a microagglutination test for Leptospira was positive for the $L$ panama at 1:400 dilution. The patient was treated with oral doxycycline, $100 \mathrm{mg}$ twice daily, as well as bilateral topical and posterior sub-Tenon injection of corticosteroid. An extracapsular cataract extraction and posterior chamber lens placement were performed shortly thereafter with prompt recovery to $20 / 20$ vision in left eye. Over the following 3 months the right eye showed rapid cataract progression with a decrease in vision to hand movement despite control of the intraocular inflammation. The patient missed all subsequent follow up visits for 6 months, but eventually returned and on examination showed complete, spontaneous absorption of the cataract in the right eye (Fig 4A). The clearing of cortical matter was so complete that the vision with a +10 dioptre lens was $20 / 40$. The patient underwent posterior chamber intraocular lens placement, with improvement of vision in the right to 20/20 (Fig 4B).

\section{Discussion}

Leptospiral uveitis was identified in 276 patients seen in the uveitis clinic at Aravind Eye Hospital during the 4 years of the study. Of these, 54 eyes of 41 patients developed visually significant cataract. Ten of these 54 eyes in eight patients showed spontaneous cataract absorption. The vast majority of patients with cataracts due to leptospirosis regained $20 / 30$ or better vision following extracapsular cataract extraction and posterior chamber intraocular lens placement.

Systemic leptospiral infection is followed by an asymptomatic, or latent, phase before the onset of the immunological phase. During the immunological phase patients often suffer from chronic headache, arthralgias, and/or uveitis. ${ }^{17}$ Uveitis associated with leptospirosis typically manifests as acute, nongranulomatous, diffuse uveitis involving one or both eyes. Occasionally, however, patients may manifest mild to severe anterior uveitis with little or no posterior segment involvement. Hypopyon, vitreous inflammation, optic disc oedema, and retinal vasculitis are reported to affect a sizeable proportion of patients. ${ }^{3}$ The intraocular inflammation due to leptospirosis usually responds promptly to treatment, but cataract and glaucoma may remain, and can cause lasting vision loss. ${ }^{18}$

Cataract is a well recognised complication of uveitis, and is particularly common in entities such as Fuchs' uveitis syndrome, juvenile rheumatoid arthritis, and pars planitis. ${ }^{15}{ }^{16}$ Cataract can develop in patients with uveitis due either to the inflammation or to chronic corticosteroid use. The vast majority of uveitic cataracts remain stable or progress only slightly once the inflammation is controlled. ${ }^{19}$

Spontaneous cataract absorption is uncommon (Table 4). Lens material has been reported to absorb, however, in patients with traumatic cataract, ${ }^{4}$ with cataract related to congenital rubella, ${ }^{5-7}$ and in age related morganian cataract. ${ }^{419}$ Spontaneous absorption of cataract in patients with uveitis appears to be rare, ${ }^{9-13}$ however, and aside from a single case report of a missing lens in a 31 year old patient who suffered from leptospiral uveitis ${ }^{20}$ has not previously been described in patients with leptospirosis.

Although a number of tests are currently available to detect anti-Leptospira serum antibodies, the microagglutination test (MAT) is the current standard for serodiagnosis. ${ }^{14}$ The MAT relies upon the agglutination of live 
Table 4 Previously reported cases of spontaneous cataract absorption

\begin{tabular}{|c|c|c|c|}
\hline Year & Author(s) & Associated findings & Patient age \\
\hline 1890 & Zentmayer $^{13}$ & $\begin{array}{l}\text { (1) Iritis } \\
\text { (2) Idiopathic }\end{array}$ & $\begin{array}{l}62 \text { years } \\
5 \text { years }\end{array}$ \\
\hline 1918 & Posey ${ }^{13}$ & Idiopathic & 14 years \\
\hline 1926 & Ballantyne $^{23}$ & Morgagnian & 65 years \\
\hline 1928 & Holloway and Gowen ${ }^{13}$ & $\begin{array}{l}\text { (1) Vitreous veils } \\
\text { (2) Vitreous opacities } \\
\text { (3) Retinochoroidal }\end{array}$ & 46 years \\
\hline 1928 & Ferrer $^{12}$ & Idiopathic & 16 years \\
\hline 1945 & Gamble $^{6}$ & Rubella & 6 months \\
\hline 1948 & Ehrlich $^{5}$ & Rubella & Congenital \\
\hline \multirow[t]{5}{*}{1952} & Marlow $^{11}$ & (1) Vitreous opacities & 17 years \\
\hline & & (2) Glaucoma & 44 years \\
\hline & & (3) Vitreous opacities & 57 years \\
\hline & & (4) Vitreous opacities & 57 years \\
\hline & & (5) Vitreous opacities & 61 years \\
\hline \multirow[t]{2}{*}{1988} & Uemura et al ${ }^{9}$ & (1) Iritis & 56 years \\
\hline & & (2) Iritis & 63 years \\
\hline \multirow[t]{2}{*}{1990} & Smith et al $l^{7}$ & Rubella & 6 weeks \\
\hline & & (1) Iritis & 56 years \\
\hline 1988 & Uemura et $\mathrm{al}^{9}$ & (2) Iritis & 63 years \\
\hline 1990 & Smith et $\mathrm{al}^{7}$ & (2) Rubella & 6 weeks \\
\hline
\end{tabular}

leptospires by specific antibodies present in an individual patient's serum. A battery of leptospira serovars, representative of each serogroup known to be present in a particular geographic region, is typically used in each MAT. During the acute phase of the illness, seroconversion or a fourfold rise in anti-Leptospira serum IgG antibodies strongly suggests the diagnosis. During the chronic or immunological phase of the illness; however, an MAT titre of $1: 100$ or more is taken as significant.

Systemic antibiotics, such as oral doxycycline or intravenous penicillin, are recognised to benefit patients with early leptospirosis, and may also have a role in the treatment of the more chronic forms of the disease, such as uveitis. $^{21}$ The primary therapy for leptospiral uveitis remains, however, corticosteroids. ${ }^{3}$ All of our patients with leptospiral uveitis and cataract responded well to oral doxycycline in association with topical, periocular, and/or systemic corticosteroids.

Leptospiral infections vary considerably from patient to patient. Such variations in severity may represent unique interactions between the microbe and the host, or may be due to intrinsic differences between the various leptospiral serotypes. ${ }^{22}$ We failed, however, to observe a statistically significant association between any particular leptospiral serovar and cataract formation. In contrast, our results suggested that the formation of cataract was determined most directly by the severity of the anterior chamber inflammation, since cataracts were observed more often in patients with a hypopyon and posterior synechiae formation (Table 2).

Spontaneous cataract absorption was first described by Saunders in 1811.5 Subsequently, several authors reported spontaneous absorption in patients with traumatic cataract, ${ }^{4}$ morgagnian cataract, ${ }^{239}$ congenital rubella cataract, ${ }^{5-7}$ and a few patients with evidence of uveitis. ${ }^{9-13}$ However, the specific causes of uveitis in these patients were not known. The mechanism by which spontaneous absorption of cataract occurs is probably not the same in all cases. Of note, however, histological studies performed on three infants who died of congenital rubella showed massive necrosis in the lenses with vacuolation and absorption of these vacuoles leading to gradual thinning of the lens. These studies also showed that the virus may persist in viable lens fibres for a considerable time, even in the presence of a neutralising serum antibody response. ${ }^{19}$ Since neither live leptospires ${ }^{24}$ nor anti-Leptospira antibodies $^{25}$ have been retrieved from the eye with leptospiral uveitis, it is not clear whether leptospires themselves or antibodies directed against leptospires have any direct role in cataract formation or absorption. Of note, however, horses are well recognised to develop a severe uveitis associated with rapid cataract formation in the setting of systemic leptospirosis, and laboratory studies have demonstrated the presence of anti-Leptospira serum antibodies in these horses that react with lens antigens, suggesting the presence of an antigenic relation between the leptospires and lens antigens, at least in the horse. ${ }^{26}$ Whether or not a this mechanism plays a part in the spontaneous cataract absorption observed in leptospiral uveitis in humans remains unknown.

In summary, cataract is a common complication of leptospiral uveitis, and appears to be associated with the uncommon phenomenon of spontaneous lens absorption, which may be both rapid and complete, in a sizeable proportion of patients. Cataract removal followed by posterior chamber intraocular lens implantation results in good recovery of vision in most patients.

We thank Ms Shantheeswari for help with preparation of the manuscript. This work was supported in part by Aravind Eye Hospital; by the DeLoris Lange Foundation, San Francisco, California; by the Proctor Foundation South Asia Research Fund; and by a Career Development Award from Research to Prevent Blindness, Inc, New York (Dr ET Cunningham).

1 Faine S. Leptospira and leptospirosis. Boca Raton: CRC Press, 1994

2 Feigin RD, Anerson DC. CRC critical reviews in clinical laboratory sciences.

3 Rathinam SR, Ratnam S, Selvaraj S, et al. Uveitis associated with an epidemic outbreak of leptospirosis. Am f Ophthalwith an epidemic o

4 Duke-Elder S. System of ophthalmology. XI. Diseases of the lens and vitreous. London: Kimpton, 1969;11:138, 220-3.
and

and vitreous. London: Kimpton, 1969;11:138, 220-3.
Ehlrich LH. Spontaneous absorption of congenital cataract following maternal rubella. Arch Ophthalmol 1948;7:332-5. 6 Gamble RC. Membranous cataract due to rubella in the mother. Am f Ophthalmol 1946;29:737.

7 Smith GTH, Shun-Shin GA, Bron AJ. Spontaneous reabsorption of a rubella cataract. $\mathrm{Br} f$ Ophthalmol 1990;74:564-5.

8 Rothova A, Suttorp-Schulton M, Frits Trefferes W, et al. Causes and frequency of blindness in patients with intraocular inflammatory disease. $\mathrm{Br} \mathcal{F}$ Ophthalmol 1996; 80:332-6.

9 Uemura A, Sameshima M, Nakao K. Complications of hypermature cataract: spontaneous absorption of lens material and phacolytic glaucoma associated with retinal perivasculitis. Fap f Ophthalmol 1988;32:35-40.

10 Holloway TB, Cowan A. Spontaneous complete absorption of a cataract lens. Arch Ophthalmol 1932;7:332-5.

11 Marlow SB. Spontaneous absorption of cataract. Trans Am Ophthalmol Soc 1952;50:283-93.

12 Ferrer H. Spontaneous resorption of juvenile cataract. $A m \mathcal{F}$ Ophthalmol 1929;11:886-7.

13 Posey, 1918, Zentmayer W, 1890, cited in Holloway TB, Cowan A. Spontaneous complete absorption of a cataract lens. Arch Ophthalmol 1932;7:332-5.

14 Sulzer CR, Jones WL. Leptospirosis (methods in laboratory diagnosis). DHEW publication No CDC 74-8275.

15 Nussenblatt RB, Palestine AG. Uveitis fundamentals and clinical practice. St Louis: Mosby Year Book, 1989:65-6.

16 Smith RE, Nozik RA. Uveitis: a clinical approach to diagnosis and management. Baltimore: Williams and Wilkins 1989:19. 7 Farr RW. Leptospirosis. Clin Infect Dis 1995;21:1-8.

18 Faine S. Guidelines for control of leptospirosis No 67. Geneva: WHO offset publ 1982:43-8.

19 Luntz MH:Clinical types of cataract. In: Tasman W, Jaeger EA, eds. Duane's clinical ophthalmology: diseases of the lens. EA, eds. Duane's clinical ophthalmology: diseases of the
Philadelphia: JB Lippincott, 1994; Vol 1, Chap 73B.

20 Sturman RM, Laval J, Weil VJ. Leptospiral uveitis. Arch Ophthalmol 1959;61:633-9. 
21 Watt G. Leptospirosis. Curr Opin Infect Dis 1997;10:149-52. 22 Turner. Leptospirosis. Medicine and Hygiene 1967;61. 22 Turner. Leptospirosis. Medicine and Hygiene 1967;61. Ballantyne AJ. Spontaneous absorption
cataract. Br $\mathcal{F}$ Ophthalmol 1926;10:202-3.

24 Alexander A, et al. Leptospiral uveitis. Report of a bacteriologically verified case. Arch Ophthalmol 1952;98:292-7.
25 Witmer H. Experimental leptospiral uveitis in rabbits. Arch

Ophthalmol 1955;53:547-59.
26 Parma AE, Cerone SI, Sansinanea SA. Biochemical analysis by SDS-PAGE and Western blotting of the antigenic relationship between Leptospira and equine ocular tissues. Vet Immunol Immunopathol 1992;3:179-85. 